\title{
Reconhecendo Potenciais de Riscos no Ambiente de Trabalho: A Importância do Curso de Capacitação de Primeiros Socorros na Segurança dos Trabalhadores
}

\author{
ROCHA, Joyce Stephany ${ }^{[1]}$, VALENTE, Vinicius Alessandro ${ }^{[2]}$
}

ROCHA, Joyce Stephany; VALENTE, Vinicius Alessandro. Reconhecendo Potenciais de Riscos no Ambiente de Trabalho: A Importância do Curso de Capacitação de Primeiros Socorros na Segurança dos Trabalhadores. Revista Científica Multidisciplinar Núcleo do Conhecimento. Edição 03. Ano 02, Vol. 01. pp 96-102, Junho de 2017. ISSN:2448-0959

\section{RESUMO}

Desconstruir a falácia de que qualquer pessoa se encontra apta para realizar o atendimento de primeiros socorros, prestando atenção ao acidentado. Somente após o conhecimento adquirido através da capacitação de primeiros socorros, uma pessoa poderá intervir no atendimento até a chegada do socorrista habilitado, sendo primordial para que a equipe multiprofissional agilize a prestação de socorro, evoluindo à etapa do diagnóstico e intervenção do paciente, posteriormente sanando suas dúvidas e compartilhando as consequências do trauma com seus familiares. É de extrema importância que o conhecimento técnico científico esteja inserido ao meio do procedimento realizado, evitando assim, riscos potenciais, sendo eles físicos ou psicológicos. Reconhecer que há potenciais de riscos em diversas instâncias é o primeiro passo para a prevenção através do olhar crítico.

Palavras-Chave: Atenção, Procedimento, Riscos, Atendimento.

\section{INTRODUÇÃO}

Ao menos uma vez na vida, cada indivíduo já presenciou alguém que sofreu um acidente de rua. Logo, notou que este mesmo é rodeado por uma multidão que de certa forma, interfere na saúde do acidentado. $\mathrm{O}$ fato é, qualquer um pode ajudar uma mulher que teve um simples desmaio, por exemplo, ou alguém que tropeçou e ralou a perna, porém quando o acidentado sofre algo mais grave, certamente necessita de um atendimento mais complexo (FILHO, 2015).

Até os dias atuais, o mundo acredita que qualquer pessoa está capacitada para intervir em um atendimento 
de primeiros socorros. A verdade é que esta ideia foi deturpada, já que na maioria das vezes o socorrista pode dificultar todo o processo. Qualquer pessoa poderá pedir ajuda, como: ligar para o atendimento, tentar acalmar o lesionado através da verbalização, entre outros. Mas será que qualquer pessoa conhece os riscos de uma infecção? Ou então sabe o momento de mobilizar totalmente aquele membro fraturado? E interromper uma hemorragia externa? Certamente não. (NOVAES, 1994)

\section{A COMPLEXIDADE DO ATENDIMENTO PRESTADO}

Primeiros socorros é o auxílio imediato prestado em caso de emergência a pessoas feridas antes do atendimento hospitalar (DICIONÁRIO PRIBERAM DA LÍNGUA PORTUGUESA, 2008-2013).

Um ambiente qualquer, sendo um lugar aberto ou fechado, apresenta riscos adventícios caracterizados por objetos pontiagudos, pisos escorregadios, falta de corrimão nas escadas, choques elétricos, queimaduras, entre outros. Esses acontecimentos independem da vontade do profissional, porém quando o mesmo realizou um curso de Primeiros Socorros ou aprendeu em sua formação acadêmica, começou a enxergar e analisar fatores internos e externos como potencial de risco; onde toda problemática arquitetônica, como os pisos molhados, são propensos a uma grande queda e possível fratura nos ossos (KAWAMOTO, 2002).

A capacitação dos profissionais em seu ambiente de trabalho, diminuem o teor de pânico. De maneira lógica, qualquer indivíduo poderá intervir no socorro? A resposta habitual seria "sim", mas a resposta correta é "não". Usando o mesmo exemplo dos pisos escorregadios e subsequentemente de uma suposta fratura. Se o ajudante não capacitado movimentar a vítima, a situação poderá se agravar muito mais, além de causar uma infecção gravíssima (ROSA, 2001).

Como observação negativa, o curso de primeiros socorros não é obrigatório em sua totalidade, mas é preciso. Porém o profissional pode se capacitar através de seu interesse e autonomia e, cobrar do seu agente superior; já que acidentes de trabalhos se tornaram comum e não abrange necessariamente apenas no horário do expediente (DRAGANOV, 2007).

Ajudar na triagem inicial da lesão agiliza o socorro, reduz sequelas, ascendem as chances de cura/sobrevivência e, se tornou um procedimento de suma importância (GOZO, 2009). Agilizar etapas através do diagnóstico clínico, para transpassar para o socorrista ainda por ligação é uma das capacitações adquiridas no treinamento de primeiros socorros como identificar se o paciente se encontra:

1. Eupneico;

2. Com abdômen abaulado ou flácido;

3. Fraturas em MMSS ou MMII e,

4. Possíveis hemorragias.

KNOBEL (2006, s/p) destaca obviamente que cada paciente apresenta distintas gravidades e, por conta disso, necessitam de intervenções e procedimentos diferentes como:

1. Massagens cardíacas;

2. Ventilação

3. Colocá-lo em posição lateral de segurança 
$\mathrm{O}$ ambiente onde a vítima se encontra determina a quantidade de agentes nocivos; como as próprias bactérias, podendo originar infecções e, por conta disso, agravar ainda mais o acidente. Se uma fratura externa acontecer no banheiro, por exemplo, obviamente o risco de piora ascende para cem porcento (FERREIRA, 2001).

CICV (2006, s/p) aponta que o socorro psicológico é indispensável em qualquer cuidado prestado. A confiança na abordagem, como:

1. Explicar ao paciente o ocorrido e o procedimento sucessor;

2. Ouvir o que a vítima sente e não o interferir quando fala;

3. Mantê-lo imóvel;

4. Responder de maneira racional e coerente as perguntas feitas pelo paciente.

A razão deve se manter em cada etapa; onde a ética priva sempre pela verdade, nunca omitindo informações sobre a saúde e conduta voltada ao ferido. Sempre deve conservar o diálogo durante o atendimento, visando se o mesmo continua consciente e orientado e assim, mais a frente sua procedência será realizada pela equipe multidisciplinar; médicos, enfermeiros, técnicos de enfermagem, fisioterapeutas, etc (MENDES, 2013).

Os sinais vitais e o exame físico, pode se dizer, são os procedimentos que mais ajudam a identificar o trauma. O exame físico como o toque no abdômen poderá identificar uma suposta hemorragia interna ou o deslocamento de algum órgão do seu lugar de origem (LOMBA, 2006).

Digamos que uma vítima esteja no chão e o socorrista foque uma luz em seus olhos e, infelizmente não acompanha o foco através da movimentação ocular, pode significar devido problema neurológico, que resultará em perda do mecanismo motor, acidente vascular cerebral, dentre outros. (SOUSA, 2010)

Agora se um paciente se encontra com a pressão e o pulso acima dos parâmetros normais, pode significar que ele está tendo um ataque cardíaco caracterizado pelo choque. Porém se for o inverso, a pressão e o pulso abaixo dos parâmetros normais, o socorrista poderá botar um pouco de na $\mathrm{Cl}$ (sal de cozinha), em via sublingual (OLIVEIRA, 2004).

Se a temperatura está baixa, pode significar que por algum evento psicológico os nutrientes estão em baixa quantidade e por consequência disso, a pressão também poderá cair. (SILVIA, 2007)

Poucas empresas se preocupam em adotar um regime de contratação de socorristas e/ou capacitação através de cursos profissionalizantes, por resultar em custo elevado através de salários mensais e materiais que auxiliarão no socorro (kit de primeiros socorros). Por conta disso, os profissionais feridos acabam recebendo verbas pelo acidente causado no local de trabalho e a reputação da empresa com grandes níveis de acidentes servindo de exemplo para as demais (SEDREZ, 1998).

Há fatores envolventes e contribuintes, onde o reparo e manutenção das instalações empresariais deverão ser rotineiras, assim, impedindo possíveis complicações que interfiram na saúde do trabalhador (MIYADAHIRA, 2008).

- Equipamento com defeito: Qualquer trabalhador tem o direito de verbalizar e simular o perigo 
antes que se concretize; como olhar para um equipamento - com o tempo de uso elevado - e determinar que o mesmo não realize suas funções de maneira adequada. Se o equipamento está inteiramente desgastado, o correto é que seja descartado e botado um novo em seu lugar. A maioria das empresas só mandam para a manutenção por um tempo e usam novamente o mesmo equipamento antigo e limitado (BERGERON, 2007).

- Eletricidade: Há um padrão normativo de fiações elétricas que deverá ser mantido sob forma rígida em todas as empresas, sejam elas de pequeno porte ou plenamente desenvolvidas. Os eletricistas devem estar altamente capacitados, assim não apresentando risco a sua própria saúde e as demais pessoas no local (MENEZES, 2011).

- Produtos Químicos: Os recipientes devem ser todos devidamente identificados para que não ocorra situações de risco elevado e constrangedoras na hora do manuseio; os tanques e as tubulações devem estar inteiramente rotuladas e, por consequência todos os funcionários deverão estar altamente treinados para o manuseio seguro de produtos químicos e nas ações de primeiros socorros (MINISTÉRIO DA SAÚDE, 2003).

- Passeios: Caso algum trabalhador atenda o pedido de um superior para deixar seu local de trabalho físico e se dirigir a outro lugar - para resolver problemas da empresa - estando em seu horário de expediente, certamente os cuidados devem ser os mesmos ou até maiores; sempre atento e tendo em mãos o kit de primeiros socorros; e sabendo para quem ligar em uma situação de emergência (DUTRA, 2005).

- Máquinas/Equipamentos: Equipamentos são ótimos para abrigar fontes infecciosas, por isso sempre mantê-los limpos e arejados, além de verificar se o botão de emergência está de fácil acesso (MANUAL DE URGÊNCIA EM PRONTO SOCORRO, 2006).

- Procedimentos de Emergência: Caso algo não saia como o previsto e o local precise ser esvaziado, é necessário que as saídas de emergência estejam totalmente sinalizadas e de alta visibilidade, sempre mantendo a ordem. As portas devem ser largas e extintores devem atender as normas de validade (HAFEN, 2002).

\section{METODOLOGIA}

A presente pesquisa é de natureza exploratória, descritiva, bibliográfica e com abordagem qualitativa. Através de artigos científicos publicados por graduandos, mestrandos e doutorandos, apresentando fonte totalmente segura, detalha-se as orientações estabelecidas sobre o tema: A importância do curso de capacitação de primeiros socorros na segurança dos trabalhadores.

\section{RESULTADOS E DISCUSSÕES}

A presente pesquisa foi desenvolvida por dois alunos graduandos em Bacharelado em Enfermagem e Terapia Ocupacional, do quinto e terceiro período respectivamente, em Belém do Pará durante o mês de março.

O desenvolvimento técnico científico acerca do processo de capacitação do treinamento de primeiros socorros se faz presente cada vez mais no âmbito da segurança. Acredita-se que, quanto mais aprendizagem na prestação de socorro, maior a notificação de casos com êxito, a exemplo do diagnóstico intervencional, sua intervenção e posteriormente à cura.

\section{CONSIDERAÇÕES FINAIS}


O objetivo central da pesquisa é ascender a ideia que uma conduta prestada no momento de pressão e pânico se torna ainda mais grave quando não se sabe que passos e ritmos a serem seguidos. $\mathrm{O}$ ambiente empregatício apresenta anormalidades em seu projeto arquitetônico capaz de intervir na saúde do trabalhador e de quem o cerca. É necessário que a intervenção seja imediata, mas sempre seguindo os protocolos ideais no momento da prestação de socorro e medidas drásticas.

\section{REFERÊNCIAS}

FILHO, A.; PEREIRA, N; LEAL, I; ANJOS, Q; LOOSE, J. A Importância do Treinamento de Primeiros Socorros no Trabalho. São Paulo: Revista Saberes, p. 1-12, 2015.

ROSA, D.; BÉRGAMO, N.; DORINI, S. Organização de primeiros socorros na empresa. Blumenau, Agosto de 2001, p. 6-41.

MENDES, Marcio. Prevenção de acidentes nos trabalhos em altura. Juiz de Fora: Faculdade de Engenharia - UFJF, p. 6-61, 2013.

SILVA, D. Manual de primeiros socorros. Minas Gerais: Alfenas, 2007.

SEDREZ, J; CHANAMÉ, L. Organização de primeiros socorros numa empresa. Fundação de Apoio à Pesquisa e Extensão Universitária (FAPEU), 1998.

SOUSA, L. Primeiros Socorros: condutas e técnicas. São Paulo: Érica ed., 2010.

BRASIL. Ministério da Saúde. Manual de Primeiros Socorros. Rio de Janeiro: Fundação Oswaldo Cruz, 2003.

BERGERON, J. D. et al. primeiros socorros. 2. ed. São Paulo: Atheneu, 2007.

CICV, Comitê Internacional da Cruz Vermelha. Primeiros socorros: em conflitos armados e outras situações de violência. Abril, 2006.

DUTRA, O. Noções de Primeiros Socorros no Trânsito. São Paulo: ABRAMET, 2005.

DRAGANOV, P. B. Cartilha de Primeiros: socorros para a Comunidade. São Paulo, 2007.

FERREIRA, A. V. S; GARCIA, E. Suporte básico de vida. Revista Social Cardiológica, v. 11, n. 2, São Paulo, 2001.

Manual de urgência em pronto-socorro. 8. ed. Guanabara: Koogan, 2006.

GOZO, F. Noções básicas de primeiro socorros. DGRH/DSS0/UNICAMP: Medicina do Trabalho, 2009.

HAFEN, B. Q. et al. Primeiros Socorros para estudantes. 7. ed. São Paulo: Manole, 2002. 
KAWAMOTO, E. E. Acidentes como socorrer e prevenir. São Paulo: E.P.U, 2002.

KNOBEL, E. Condutas do paciente grave. 3. ed. São Paulo: Editora Atheneu, 2006.

LOMBA, M.; LOMBA, A. Emergências e Atendimentos Pré-Hospitalares. v. 3, Olinda: Objetivo Saúde, 2006.

MIYADAHIRA, A. M. K. et al. Ressuscitação cardiopulmonar com a utilização do desfibrilador externo semiautomático: avaliação do processo ensino aprendizagem. Rev. esc. enferm. USP, v. 42, n. 3. São Paulo: set/2008.

MENEZES PINTO, M. O. Acidentes e causas. Araras: Curso de Especialização em Psicologia do Trânsito - UNAR, 2011.

NOVAES, J. S.; NOVAES, G. S. Manual de Primeiros Socorros para Educação Física. Rio de Janeiro: Sprint, 1994.

OLIVEIRA, B. F. M.; PAROLIN, M. K. F.; TEIXEIRA JR., E.V. Trauma Atendimento Pré Hospitalar. São Paulo: Atheneu, 2004.

[1] Graduanda em Enfermagem no Centro Universitário do Estado do Pará.

[2] Graduando em Terapia Ocupacional na Escola Superior da Amazônia.

\section{PUBLIQUE SEU ARTIGO CIENTÍFICO EM:}

https://www.nucleodoconhecimento.com.br/enviar-artigo-cientifico-para-submissao 